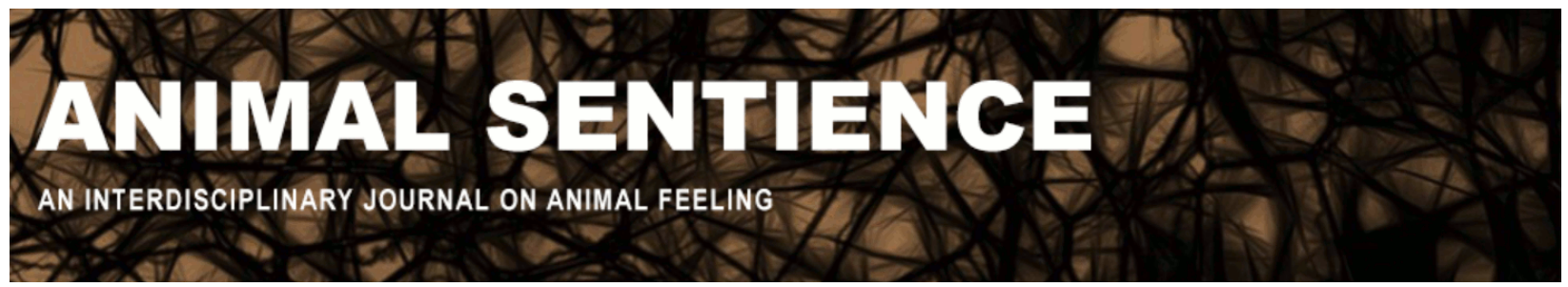

Palagi, Elisabetta (2019) Sharing emotions builds bridges between individuals and between species. Animal Sentience 23(33)

DOI: $10.51291 / 2377-7478.1413$

Date of submission: 2019-02-10

Date of acceptance: 2019-02-18

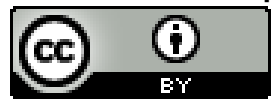

This article has appeared in the journal Animal

Sentience, a peer-reviewed journal on animal

cognition and feeling. It has been made open access,

free for all, by WellBeing International and deposited

in the WBI Studies Repository. For more information,

please contact

wbisr-info@wellbeingintl.org.

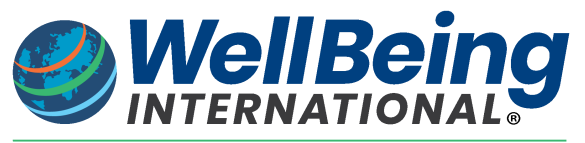

SOLUTIONS FOR PEOPLE, ANIMALS AND ENVIRONMENT 


\title{
Sharing emotions builds bridges between individuals and between species
}

\author{
Commentary on Chapman \& Huffman on Human Difference
}

\author{
Elisabetta Palagi \\ Unit of Ethology, Department of Biology, University of Pisa, Italy
}

\begin{abstract}
Many animal species express, perceive and share emotions. These abilities have been favoured by natural selection because they allow subjects to respond to various situations in an appropriate way, thus facilitating survival and increasing fitness. The same-face/same-emotion phenomenon is at the basis of sharing feelings and emotions. Recent studies show that this capacity is not unique to humans and that it plays an important role in creating cohesive societies in many different species.
\end{abstract}

\footnotetext{
Elisabetta Palagi, Associate Professor (University of Pisa, Italy), publishes extensively in the fields of sociobiology, comparative psychology, and anthropological sciences. Her topics are multimodal communication, evolutionary significance of play, conflict resolution, and empathy in human/nonhuman animals. She has published on over 10 primate species, dogs, wolves, meerkats, seals and horses. Website
}

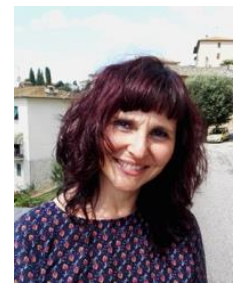

1. Introduction. In their interesting target article, Chapman \& Huffman (2018) deal with a muchdisputed issue: are humans unique compared to other animals? The authors present many different criteria that have been used to put human beings on the "golden pedestal" of uniqueness with respect to other animals. Across the years, all the criteria used to create a separation between us and "the others" have failed: humans are not the only animals who are able to use tools or medicines, or able to build complex structures. I would like to introduce a point that builds a bridge between humans and other animals: the ability to experience, express and resonate emotions. All mammals (and perhaps many other non-mammal species, future studies may show) express and perceive emotions. This capacity has adaptive value because it allows subjects to respond to diverse situations in an appropriate way, facilitating survival and increasing fitness (Mendl et al., 2010).

2. Same-Face/Same-Emotion Mechanism. Facial expressions convey information about the motivations and emotions of the producer. Correctly decoding a facial expression can improve the diffusion of social messages which often produce synchronization and group cohesion (Palagi \& Scopa, 2017). In our own species, this kind of communication is so pervasive that it often affects rational decisions, opinions, and beliefs (de Waal and Preston, 2017). Rapid facial mimicry (RFM) is a fast (less than $1 \mathrm{~s}$ ), automatic, congruent response in which subjects involuntarily mimic one another's facial expressions (Davila-Ross et al., 2008; Palagi et al., 2015; Scopa \& Palagi, 2016) (Figure 1). RFM is grounded in the automatic perception-action coupling of sensorimotor information that occurs in motor areas of the brain. While observing a specific facial expression, the observer's motor activation results in the experience of a matching emotional state. Seeing a 
facial expression activates sub-cortical brain areas, such as limbic structures, which are active both when the subject feels an emotion, and when the subject observes the same emotion in the facial expression of others (emotional resonance). Hence, same face, same emotion.

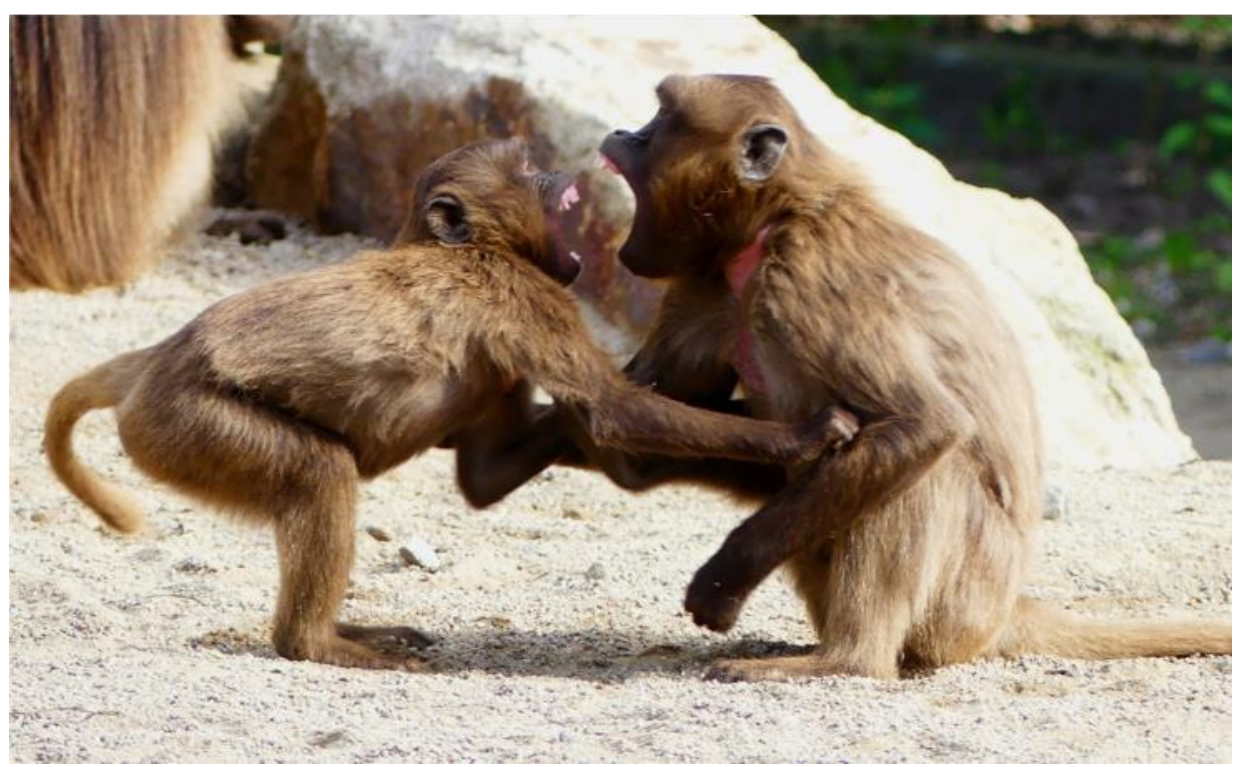

Figure 1: Rapid facial mimicry (RFM) between a juvenile and an infant gelada baboon (Theropithecus gelada) during a play-fighting session. Those sessions punctuated by RFM last longer than those with only play faces but no RFM. (Photo: Elisabetta Palagi)

3. Importance of Emotional Sharing in Forming Cohesive Societies. In humans, RFM is thought to be important in connecting two individuals emotionally. Its importance in fostering social bonds between people, together with observations of consolation and support in non-human animals (Clay et al., 2018), was what had led to the hunch that RFM may not be unique to human beings. The first evidence came from Davila-Ross and coworkers (2008), who reported that orangutans (Pongo pygmaeus) replicate the play face of their playmates in a very fast $(<1 \mathrm{~s})$ and automatic way. Such responses are thought to be homologous with smiling contagion in humans. Play is a widespread behaviour, punctuated by specific facial expressions which are homologous across mammals (e.g., play faces). Play generates a positive mood, creating the basis for strong social relationships (Palagi, 2018). Play is hence a very fertile domain for comparative studies on the capacity to share emotions.

Since 2008 , there have been many other studies of whether RFM is present during playful contacts not only in primates (Pan troglodytes and Gorilla gorilla, Palagi et al., 2018; Theropithecus gelada, Mancini et al., 2013; Macaca spp., Scopa \& Palagi, 2016) but also in other mammals (Canis lupus familiaris, Palagi et al., 2015). RFM has been found in all the species living in tolerant societies. Its distribution follows the empathic gradient observed in humans. The higher the familiarity of the interacting subjects, the higher the frequency of RFM. In primates as well as dogs, the RFM leads to longer interactions, suggesting it has a direct influence on the emotional and motor synchronization between the players. If emotional sharing provides such valuable benefits in shaping complex societies, why should it have been naturally selected only in our own species? 


\section{References}

Chapman C.A., \& Huffman, M.A. (2018) Why do we want to think humans are different? Animal Sentience 23(1).

Clay Z., Palagi E., \& de Waal, F.B.M. (2018) Ethological approaches to empathy in primates. In K. Z. Meyza \& E. Knapska (Eds.), Neuronal correlates of empathy: From rodent to human (pp. 53-66).

Davila-Ross, M., Menzler, S., \& Zimmermann, E. (2008) Rapid facial mimicry in orangutan play. Biology Letters, 4, 27-30.

de Waal, F.B.M., \& Preston, S.D. (2017) Mammalian empathy: Behavioural manifestations and neural basis. Nature Reviews Neuroscience, 18, 498-509.

Mancini, G., Ferrari, P.F., \& Palagi, E. (2013) Rapid facial mimicry in geladas. Scientific Reports, 3, 1527.

Mendl, M., Burman, O.H.P., \& Paul, E.S. (2010) An integrative and functional framework for the study of animal emotion and mood. Proceedings of the Royal Society, 277, 2895-2904.

Palagi, E. (2018) Not just for fun! social play as a springboard for adult social competence in human and non-human primates. Behavioral Ecology and Sociobiology, 72, 90.

Palagi, E., \& Scopa, C. (2017) Integrating Tinbergen's inquiries: Mimicry and play in humans and other social mammals. Learning \& Behavior, 45, 378-389.

Palagi, E., Nicotra V., \& Cordoni, G. (2015) Rapid mimicry and emotional contagion in domestic dogs. Royal Society Open Science, 2, 150505.

Palagi, E., Norscia I., Pressi S., \& Cordoni, G. (2018) Facial mimicry and play: A comparative study in chimpanzees and gorillas. Emotion.

Scopa, C., \& Palagi, E. (2016) Mimic me while playing! Social tolerance and rapid facial mimicry in macaques (Macaca tonkeana and Macaca fuscata). Journal of Comparative Psychology, 130, 153-161. 